\title{
Caracterização genética e estrutura populacional de galinhas crioulas Canela-Preta
}

\author{
Débora Araújo de Carvalho(1), Cristina Moreira Bonafé(1), Maria Del Pilar Rodriguez-Rodriguez(1), \\ Marcos Jacob de Oliveira Almeida ${ }^{(2)}$, Jose Lindenberg Rocha Sarmento ${ }^{(3)}$, \\ Fabio Barros Britto ${ }^{(3)}$ e Martinho de Almeida e Silva(1)
}

\begin{abstract}
(1)Universidade Federal dos Vales do Jequitinhonha e Mucuri, Departamento de Zootecnia, Campus JK, Rodovia MGT 367, Km 583, no 5.000, Alto da Jacuba, CEP 39100-000 Diamantina, MG, Brasil. E-mail: deborabie@hotmail.com, crisbonafe@gmail.com, rodrigpilar@gmail.com, martinhomas@hotmail.com ${ }^{(2)}$ Embrapa Meio-Norte, Transferência de Tecnologia, Avenida Duque de Caxias, no 5.650, Buenos Aires, CEP 64006-245 Teresina, PI, Brasil. E-mail: jacob_marcos@hotmail.com (3)Universidade Federal do Piauí, Departamento de Zootecnia e Ciências Biológicas, Campus Universitário Ministro Petrônio Portella, Ininga, s/no, CEP 64049-550 Teresina,

PI, Brasil. E-mail: sarmento@ufpi.edu.br, fbbritto@ufpi.edu.br
\end{abstract}

Resumo - O objetivo deste trabalho foi caracterizar geneticamente e avaliar a estrutura populacional de galinhas crioulas Canela-Preta de três plantéis pertencentes aos municípios de Teresina, Oeiras e Queimada Nova, no Estado do Piauí. Utilizaram-se 12 marcadores microssatélites e amostras de DNA de 118 galinhas. Após a extração do DNA, os marcadores microssatélites foram amplificados por meio da técnica de reação em cadeia da polimerase (PCR). Efetuaram-se análises estatísticas da estimativa de heterozigosidades observada e esperada, análise de variância molecular, análise de componentes principais, estatística $\mathrm{F}$ de Wright e análise de estrutura populacional com base em análise bayesiana. As análises de diferenciação genética (Amova) sugerem baixa diferenciação entre os núcleos avaliados, o que indica se tratar geneticamente de um único grupo. Os resultados da estatística $\mathrm{F}$ indicaram tendência de endogamia dos plantéis estudados. $\mathrm{O}$ gráfico de dispersão e análise bayesiana, usado para mostrar a estrutura das aves Canela-Preta, sugeriu a existência de quatro grupos genéticos e revela que há fluxo gênico entre os plantéis analisados. Os marcadores moleculares microssatélites avaliados apresentam-se polimórficos, o que mostra alta variação nas amostras e revela sua eficiência no estudo de caracterização. Os resultados são indicativos de que as galinhas Canela-Preta estão geneticamente estruturadas.

Termos para indexação: Gallus gallus, microssatélites, polimorfismo, variabilidade genética.

\section{Genetic characterization and population structure of Canela-Preta creole chicken}

\begin{abstract}
The objective of this work was to genetically characterize and evaluate the population structure of Canela-Preta creole chicken of three breeding stocks belonging to the municipalities of Teresina, Oeiras and Queimada Nova, in the state of Piauí, Brazil. Twelve microsatellite markers and DNA samples from 118 chickens were used. After DNA extraction, the microsatellite markers were amplified by polymerase chain reaction (PCR). Statistical analyses of the observed and expected heterozygosity estimates, analysis of molecular variance, principal components analysis, Wright's F-statistics, and analysis of population structure based on Bayesian analysis were performed. The analyses of genetic differentiation (using Amova) suggested low differentiation between the evaluated nucleuses, indicating this group as genetically unique. The results of the F-statistics indicated endogamy trend of the breeding stocks studied. Scatter plot and Bayesian analysis, used to show the structure of Canela-Preta birds, suggested the existence of four genetic groups and revealed that there is gene flow between the breeding stocks analysed. The evaluated microsatellite molecular markers showed to be polymorphic, which shows high variation in the samples and reveals their effectiveness in the study of characterization. The results indicate that Canela-Preta chickens are genetically structured.
\end{abstract}

Index terms: Gallus gallus, microsatellites, polymorphism, genetic variability.

\section{Introdução}

Nos anos 1930, a avicultura industrial apresentou importante avanço no Brasil; nesse contexto, as raças crioulas foram sendo substituídas. Consequentemente, algumas dessas raças entraram em risco de extinção. Porém, em 1980, houve uma crescente demanda dos pequenos criadores por aves crioulas mais rústicas, 
em virtude da valorização de produtos naturais e da rusticidade destas, próprias para criação em sistemas tradicionais. Contudo, para atender a essa demanda, se fez necessária a busca de aves crioulas adaptadas a cada região. Por conseguinte, as raças crioulas tornaram-se potencialmente lucrativas (Fonteque et al., 2014).

Em algumas regiões, as galinhas crioulas CanelaPreta também são conhecidas como "Jacu" e se caracterizam principalmente por possuírem tarso e falanges de coloração preta, e corpo predominantemente preto com pigmentações nas penas do pescoço nas cores branca, dourada ou vermelha e por possuírem carne de coloração mais escura, comparada à das demais galinhas crioulas.

A caracterização genética de galinhas crioulas vem sendo feita por alguns países, como Espanha, Índia e Peru, com intuito de evitar a perda desse importante material genético. Porém, apenas $25 \%$ das raças de galinhas crioulas fazem parte de algum tipo de programa de conservação, logo, são necessárias pesquisas que ajudem a elucidar a genética destas raças. Consequentemente, é fundamental estudar e calcular a variabilidade genética dessas aves, pois está diretamente relacionada com a manutenção da variabilidade interracial, evitando a extinção das raças e a manutenção da variabilidade intrarracial, evitando a erosão genética (Clementino, 2010).

Marcadores moleculares têm sido utilizados para estudos de caracterização genética de populações de galinhas crioulas. O mais utilizado é o microssatélite, sequências simples repetidas (Simple Sequence Repeats - SSR) de DNA. Geralmente, são repetições de mono, tetra e, principalmente, dinucleotídeos, e estão localizados entre os genes ou dentro de íntrons (Dávila et al., 2009).

As galinhas crioulas brasileiras são rústicas, e acredita-se que apresentam elevada variabilidade genética. Existem poucos trabalhos que o comprovem, contudo, é importante a existência de pesquisas científicas que evidenciem esse alto polimorfismo, pois tornariam a manutenção e conservação dessas aves imprescindível. Além disso, o polimorfismo gênico é fonte de alelo para programas de melhoramento genético dos animais de produção (Fonteque et al., 2014).

As variações gênicas dentro da população são relevantes para qualquer espécie, não apenas por favorecerem o processo de especiação, mas também por serem um dos pilares para elaboração de programas de melhoramento genético e conservação. Mariante et al. (2008) confirmam que as raças crioulas apresentam maior variabilidade gênica que as raças exóticas, ressaltando a importância de que estas sejam conservadas.

O objetivo deste trabalho foi caracterizar geneticamente e avaliar a estrutura populacional de galinhas crioulas Canela-Preta de três plantéis pertencentes aos municípios de Teresina, Oeiras e Queimada Nova, no Estado do Piauí, Brasil.

\section{Material e Métodos}

Utilizou-se um total de 118 galinhas crioulas Canela-Preta de plantéis pertencentes ao programa Projeto Produtores do Futuro no Piauí, situados em três municípios do estado, sendo Teresina localizada a $05^{\circ} 05^{\prime} 20^{\prime \prime} \mathrm{S} \quad 42^{\circ} 48^{\prime} 07^{\prime \prime} \mathrm{W}$ (38 amostras), Oeiras localizada a $07^{\circ} 01^{\prime} 30^{\prime \prime} \mathrm{S} 42^{\circ} 07^{\prime} 51^{\prime \prime W}$ (37 amostras) e Queimada Nova localizada a $08^{\circ} 34^{\prime} 44^{\prime \prime S} 41^{\circ} 25^{\prime} 08^{\prime \prime} \mathrm{W}$ (43 amostras). Para as análises experimentais, foi realizada coleta de material biológico (sangue da veia ulnar) sobre papel-filtro, após secagem em temperatura ambiente, que foi colocado em envelopes devidamente identificados. Este estudo conta com o registro $\mathrm{n}^{-}$ 04412014 do Comitê de Ética de Experimentação Animal da Universidade Federal dos Vales de Jequitinhonha e Mucuri (UFVJM).

Os procedimentos laboratoriais foram realizados no laboratório de Genética Molecular Aplicada do Departamento de Zootecnia da UFVJM, localizado no Município de Diamantina, MG. Utilizou-se fragmento de cada amostra, de $0,5 \mathrm{~cm}$ do papelfiltro, para o procedimento da extração do DNA genômico, que, por sua vez, foi realizado usando o protocolo de extração salina estabelecido por Lopera-Barrero et al. (2008). A quantificação do DNA foi feita no espectrofotômetro com amplitude de onda de $260 \mathrm{~nm}$, e as amostras foram diluídas para uma concentração de $10 \mathrm{ng} \mu \mathrm{L}^{-1}$. A integridade do DNA foi verificada em eletroforese horizontal usando um gel de agarose $1 \%$, a $70 \mathrm{~V}$ por 70 minutos e, posteriormente, capturou-se a imagem no sistema fotográfico UV312.

A amplificação dos fragmentos de DNA desejados foi realizada pela técnica de Reação em Cadeia de Polimerase (PCR), a partir do DNA total. Foram utilizados 12 loci de microssatélites desenhados para espécie Gallus gallus domesticus: LEI0192, LEI0234, 
LEI0248, MCW0081, MCW0183, LEIO0209, LEI0212, LEI0217, LEI0221, LEI0237, LEI0258 e MCW0213.

O DNA foi amplificado em volume de reação de $16 \mu \mathrm{L}$, e cada reação continha 50 ng de DNA, 2,5 $\mu \mathrm{L}$ de tampão 10X (100 mM TrisHCl, pH 8,3, $500 \mathrm{mM}$ $\mathrm{KCl}), 1-2,5 \mu \mathrm{L}(20-50 \mathrm{mM})$ de $\mathrm{MgCl}_{2}, 2 \mu \mathrm{L}$ da mistura de dNTP (0,2 mM de dATP, dCTP, dGTP e dTTP), $0,8 \mu \mathrm{M}$ de cada iniciador, e 0,5 unidade de Taq DNA polimerase (Ludwig Biotec). A PCR foi realizada nas seguintes condições: 1 minuto de desnaturação inicial a $94^{\circ} \mathrm{C} ; 30$ ciclos de 30 segundos de desnaturação a $94^{\circ} \mathrm{C}, 30$ segundos de anelamento a $49-64^{\circ} \mathrm{C}$, dependendo do par de iniciadores, e 50 segundos de extensão a $72^{\circ} \mathrm{C}$; e uma extensão final de 5 minutos a $72^{\circ} \mathrm{C}$.

Os produtos da PCR foram visualizados em gel de poliacrilamida desnaturante a $10 \%$ (acrilamida:bisacrilamida - 29:1), ureia $6 \mathrm{~mol} \mathrm{~L}^{-1}$, e foram corados com nitrato de prata, conforme Bassam et al. (1991). Foi utilizado marcador de DNA de 50 pares de bases (pb) (Invitrogen), para auxiliar na determinação do tamanho dos fragmentos.

O programa GenAlEx 6.5 (Peakall \& Smouse, 2012) foi usado para calcular as estimativas de heterozigosidades esperada $(\mathrm{He})$ e observada $(\mathrm{Ho})$.

O número efetivo das populações totais foi calculado pela seguinte equação: $\mathrm{N}_{\mathrm{e}}=\left[\left(4 \mathrm{~N}_{\mathrm{m}} \mathrm{N}_{\mathrm{f}}\right) /\left(\mathrm{N}_{\mathrm{m}}+\mathrm{N}_{\mathrm{f}}\right)\right]$; em que $\mathrm{N}_{\mathrm{e}}$ é o tamanho efetivo populacional, $\mathrm{N}_{\mathrm{m}}$ é número de machos e $\mathrm{N}_{\mathrm{f}}$ é o número de fêmeas. As estimativas F de Wright (Fis, Fct, Fit), bem como a variância genética global entre os núcleos, estimadas por análise de variância molecular - Amova (Excoffier et al., 1992), a matriz de dissimilaridade, os componentes principais (PCoA) e o gráfico de dispersão também foram calculados pelo programa GenAlEx 6.5.

As estimativas $F$ utilizam coeficientes de endocruzamento para medir a variabilidade intra e interpopulacional. Fis é o coeficiente de endogamia ou índice de fixação dentro dos indivíduos relacionados à população, que mensura a redução da heterozigosidade de um indivíduo em virtude de acasalamentos aleatórios na subpopulação. O coeficiente de endogamia dos indivíduos com relação ao total (Fit) considera, além dos acasalamentos ao acaso, a diferenciação no âmbito genético entre as subpopulações. O coeficiente de endogamia dentro da subpopulação com relação ao total (Fst) fornece a percentagem total da diversidade genética que está distribuída entre as subpopulações (Wright, 1951).

A Amova entre e dentro das populações e indivíduos, analisada no mesmo programa, utilizou 10.000 permutações para os cálculos. Esta levou em consideração o agrupamento das amostras a priori, no qual estas foram organizadas por municípios. O programa Structure, versão 2.3.4, foi utilizado para definir o número de grupos $(\mathrm{K})$ mais provável nas amostras coletadas, por meio de métodos Bayesianos sem informações a priori sobre a origem das amostras, conforme Pritchard et al. (2000). Foram utilizadas 150.000 simulações de Cadeias de Markov Monte Carlo com burn in de 50.000, modelo de ancestralidade admixture, e testados valores de $\mathrm{K}$ variando de 1 a 7, com cinco interações. A determinação do $\mathrm{K}$ mais provável em relação aos propostos foi realizada utilizando valores de $\Delta \mathrm{K}$ (Evanno et al., 2005), como segue: $\Delta \mathrm{K}=\mathrm{m} \Delta \mathrm{L}^{\prime}(\mathrm{K}+1)$ - $\mathrm{L}^{\prime}(\mathrm{K}) / \mathrm{s}[\mathrm{L}(\mathrm{K})]$, em que: $\mathrm{L}: \mathrm{L}^{\prime}(\mathrm{K})=\mathrm{L}(\mathrm{K})$ - L(K - 1)/ s [L(K)]; sendo: m, média; $\mathrm{s}$, desvio-padrão, e $\mathrm{K}$, número de grupos propostos.

\section{Resultados e Discussão}

Os dados observados nos 12 marcadores microssatélites selecionados indicaram valores médios de heterozigosidade observada (Ho) de 0,674 e de heterozigosidade esperada $(\mathrm{He})$ de 0,887 . A He e Ho variaram pouco entre os plantéis (Tabela 1). Os polimorfismos genéticos apresentam relevância em análises das relações genéticas entre subpopulações de uma espécie (Hartl \& Clark, 2010). Estudos com galinhas mostram a importância dos microssatélites em análises de parentesco e diversidade genética, e as informações oriundas desses marcadores microssatélites podem auxiliar no planejamento de cruzamentos tecnificados, reduzindo valores expressivos de taxas endogâmicas e perda de alelos no melhoramento dos animais (Qu et al., 2006; Fonteque et al., 2014).

Os valores médios de Ho nos plantéis indicam que existe um excesso de homozigotos com relação à He (Tabela 1), e os plantéis que apresentaram a maior e menor diferença entre He e Ho foram Queimada Nova $(0,242)$ e Oeiras $(0,162)$, respectivamente. Estes valores podem estar sendo influenciados pelo intercâmbio de alguns reprodutores de galinhas Canela-Preta durante a formação dos plantéis, o que pode ser sustentado 
em virtude da localização geográfica dos municípios estudados, em que Oeiras se encontra no meio e possivelmente tem recebido ou intercambiado material genético dos plantéis vizinhos (Teresina e Queimada Nova), prática comumente realizada pelos produtores.

Os valores totais médios da heterozigosidade dos plantéis (Ho: 0,674 e He: 0,887), do presente estudo, de galinhas Canela-Preta foram considerados intermediários. Foram considerados níveis altos aqueles $>0,7$, e baixos aqueles $<0,5$ (Clementino, 2010). Outras pesquisas com galinhas crioulas mostraram níveis baixos de média de heterozigosidade: $\mathrm{Ho}=0,491$ e $\mathrm{He}=0,756$ em galinhas crioulas brasileiras produtoras de ovos azuis (Fonteque et al., 2014); $\mathrm{Ho}=0,380$ e $\mathrm{He}=0,475$ em frangos nativos de Turquia (Kaya \& Yildiz, 2008); e Ho=0,5 e $\mathrm{He}=0,6$ em frangos de raças indígenas (Chatterjee et al., 2015). No entanto, foram encontrados níveis altos de heterozigosidade $(\mathrm{Ho}=0,785$ e $\mathrm{He}=0,687)$ em ecótipos de galinhas brasileiras (Clementino et al., 2010). Isso mostra, assim, que os plantéis de raças crioulas representam uma fonte de genes para programas de preservação e podem-se mostrar promissórios para programas de melhoramento genético.

A Amova demonstrou que a maior parte da variabilidade genética está uniformemente distribuída dentro dos plantéis (97\%). O alto valor obtido mostrou que as localidades não estão apresentando características genéticas marcadamente distintas. A variância entre plantéis/populações representou apenas 3\% da variação total (Tabela 2), e isso demonstra que os indivíduos estudados dos três plantéis podem ser considerados como grupo geneticamente estruturado numa única população. Esses dados corroboram a maioria dos estudos de diversidade (Muchadeyi et al., 2007; Clementino, 2010), em que a variabilidade genética dentro das populações é geralmente maior que entre populações.

As estatísticas $\mathrm{F}$ de Wright, que também são consideradas análises de estrutura populacional, neste estudo podem indicar que, no geral, as aves estudadas formaram subgrupos genéticos com correspondência aos seus respectivos municípios - porém, com baixa diferenciação genética $(<0,05)$, como observado no valor de Fst $(0,029)$. Estudos de comparação que usam marcadores moleculares microssatélites mostraram valores moderados de Fst $(0,05-0,25)$ em duas linhagens de frangos Fst $(0,102)$, e em cinco raças de galinhas suecas locais Fst $(0,180)$ (Abebe et al., 2015; Das et al., 2015). Os valores baixos de Fst encontrados no presente estudo podem indicar, como mencionado

Tabela 1. Média e erro padrão para diversas estimativas ao longo de cada lócus para os plantéis de galinhas crioulas Canela-Preta nos municípios de Teresina, Oeiras e Queimada Nova, Estado do Piauí.

\begin{tabular}{|c|c|c|c|c|c|c|}
\hline Plantel & & $\mathrm{N}^{(1)}$ & $\mathrm{Ho}^{(2)}$ & $\mathrm{He}^{(3)}$ & $\mathrm{UHe}^{(4)}$ & $\mathrm{F}^{(5)}$ \\
\hline \multirow[t]{2}{*}{ Teresina } & Média & 36,3 & 0,650 & 0,887 & 0,899 & 0,269 \\
\hline & Desvio & & 0,058 & 0,017 & 0,017 & 0,092 \\
\hline \multirow[t]{2}{*}{ Oeiras } & Média & 36,3 & 0,727 & 0,889 & 0,901 & 0,172 \\
\hline & Desvio & & 0,059 & 0,024 & 0,025 & 0,081 \\
\hline \multirow[t]{2}{*}{ Queimada Nova } & Média & 41,3 & 0,643 & 0,885 & 0,896 & 0,256 \\
\hline & Desvio & & 0,063 & 0,021 & 0,022 & 0,067 \\
\hline \multirow[t]{2}{*}{ Total } & Média & 38 & 0,674 & 0,887 & 0,899 & 0,233 \\
\hline & Desvio & & 0,034 & 0,012 & 0,012 & 0,046 \\
\hline
\end{tabular}

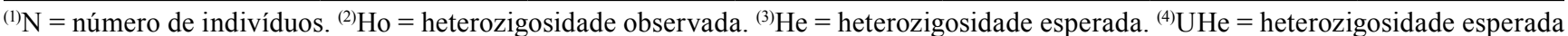
com fator de correção para tamanho amostral. ${ }^{(5)} \mathrm{F}$, índice de fixação de Wright [1 - $\left.(\mathrm{Ho} / \mathrm{He})\right]$.

Tabela 2. Estatísticas da análise de variância molecular (Amova), utilizando 12 loci de microssatélites em plantéis de galinhas crioulas Canela-Preta dos municípios Queimada Nova, Oeiras e Teresina, Estado do Piauí.

\begin{tabular}{|c|c|c|c|c|c|c|}
\hline Fontes de variação & GL & Soma dos quadrados & Quadrado médio & Componentes de variação & Percentagem (\%) & $\mathrm{F}$ (valor p) \\
\hline Entre populações & 2 & 39,075 & 19,538 & 0,160 & 3 & $0,029^{(1)}(0,001)$ \\
\hline Entre indivíduos & 115 & 802,870 & 6,981 & 1,539 & 27 & $0,283^{(2)}(0,001)$ \\
\hline Dentro de indivíduos & 118 & 460,500 & 3,903 & 3,903 & 70 & $0,303^{(3)}(0,001)$ \\
\hline Total & 235 & $1.302,445$ & & 5,602 & 100 & - \\
\hline
\end{tabular}

${ }^{(1)}$ Fst, índice de fixação entre núcleos. ${ }^{(2)}$ Fit, índice de fixação entre indivíduos. ${ }^{(3)}$ Fis, índice de fixação dentro de indivíduos. 
anteriormente, que os plantéis pertencem a um mesmo grupo genético.

Com relação às estimativas de variação genética, observou-se que, em cada local amostrado, houve valores positivos para índice de fixação ou de endogamia (F), o que pode influir nas frequências genotípicas (McManus et al., 2011) e mostrar o grau de endocruzamento dentro de indivíduos do mesmo plantel. O plantel Oeiras apresentou o menor valor de $F(0,172)$, seguido por Queimada Nova $(F=0,256)$, e o maior valor $F(0,259)$ foi observado no plantel de Teresina; tal como o valor médio de fixação Fis $(0,303)$ dos plantéis indica deficit global heterozigosidade.

Contudo, o possível fluxo genético entre os plantéis em virtude do intercâmbio de reprodutores pode estar influenciando o menor índice de endogamia no plantel de Oeiras, de tal forma que os plantéis mais distantes, como Teresina e Queimada Nova, apresentem valores similares de $\mathrm{F}$ em virtude da distância geográfica que existe entre estas e da dificuldade de intercâmbio genético. $\mathrm{O}$ valor de Fit $(0,283)$ indica um favorecimento de homozigose de $27 \%$ nos plantéis, podendo evidenciar genes derivados de um ancestral comum.

Outro fator que pode sugerir um maior valor $\mathrm{F}$ no plantel de Teresina é o fato de ser o primeiro plantel de conservação formado do projeto com galinhas Canela-Preta, e a maioria do material genético formador foi proveniente de comunidades quilombolas e indígenas da região de Queimada Nova, o que pode resultar num plantel formado a partir de um número pequeno de animais da população e que pode influenciar num maior número de homozigotos.

Por outro lado, esse plantel conserva seus reprodutores até eles atingirem o máximo de tempo de reprodução, tempo estipulado pelos produtores, podendo um reprodutor ficar no plantel até por cinco anos aproximadamente. Já nos plantéis de Queimada Nova e Oeiras, os reprodutores só permanecem por um ano e meio no plantel, evitando, assim, o acasalamento com sua progênie. Mesmo que a reprodução ocorra ao acaso, alguns trabalhos mostram que existe dominância entre machos (Favati et al., 2014), o que provavelmente pode levar ao favorecimento de alguns alelos e, assim, ao aumento de índices de fixação (Fis, Fst, Fit) no plantel e entre os plantéis.

Dos 118 indivíduos amostrados, ao fazer o cálculo do tamanho efetivo, esse número reduziu-se para
64,6 indivíduos, o que pressupõe que está havendo acasalamentos entre indivíduos aparentados. Esse tipo de acasalamento influencia o incremento da endogamia e o desvio do equilíbrio de HardyWeinberg (EHW). Estes resultados mostram que as populações podem estar sendo influenciadas pelas mudanças nas frequências alélicas (Rengmark et al., 2006) e pelo efeito de gargalo de garrafa ou efeito fundador que pode ter ocorrido durante a formação dos plantéis.

O gráfico de dispersão gerado a partir da matriz de dissimilaridade apresentou elevada variabilidade genética nas galinhas Canela-Preta (Figura 1), com a formação de quatro subgrupos distintos, em que três correspondem aos municípios nos quais foram coletadas as amostras, e acredita-se que a formação do quarto grupo corresponda provavelmente a animais com características próprias, que podem estar passando por um processo de microevolução ou pode ser um material mestiçado com genética externa, que não são necessariamente materiais exóticos, e sim de animais que foram inseridos recentemente nos plantéis.

A abordagem bayesiana implementada no software Structure foi usada para encontrar a estrutura da população estudada, com base na associação das frequências alélicas e proposição de mistura entre os indivíduos dos plantéis avaliados sem informação a priori sobre ancestralidade. A estrutura de populações, embasada pelo método bayesiano, apresentou o maior valor médio $\Delta \mathrm{K}$, em que $\mathrm{K}=4$ (Figura $2 \mathrm{~A}$ ). Esses resultados indicam que a análise de agrupamento do programa Structure pode proporcionar precisas representações das relações genéticas existentes entre os plantéis de galinhas Canela-Preta, o que sugere que existem quatro subgrupos genéticos, corroborando o gráfico de dispersão. Outros autores também têm usado inferências bayesianas para analisar estruturas de populações de galinhas (Abebe et al., 2015; Kumar et al., 2015), apresentando-se como uma técnica eficiente para estrutura de populações.

Observa-se, na Figura 2 B, que o plantel Queimada Nova apresentou predominância de dois materiais genéticos diferentes (cores verde e azul); no entanto, os plantéis de Oeiras e Teresina apresentaram predominância de material genético nas cores vermelha e amarela, respectivamente. Acredita-se que esses resultados podem estar relacionados com as localizações geográficas dos plantéis e a origem.

Pesq. agropec. bras., Brasília, v.51, n.11, p.1899-1906, nov. 2016 DOI: $10.1590 / \mathrm{S} 0100-204 X 2016001100012$ 
Analisando o primeiro plantel do Município de Queimada Nova, que fica localizado perto das fronteiras com os estados de Pernambuco e Bahia, pode-se sugerir que, provavelmente, durante a história das galinhas da raça Canela-Preta, existiu um recâmbio genético com galinhas Canela-Preta das fronteiras. Porém, não se pode afirmar isso, pois ainda não há estudos sobre galinhas Canela-Preta nos estados da Bahia e Pernambuco. Por outro lado, em virtude da proximidade com o segundo plantel, de Oeiras, localizado a $190 \mathrm{~km}$, aproximadamente, pode-se indicar que existe um intercâmbio de material genético. Certamente, os gráficos de dispersão e de formação de subgrupos mostram que o plantel de Queimada Nova possui uma alta variabilidade genética e que existe fluxo genético com o plantel de Oeiras.

Em segundo lugar, o plantel de Oeiras, no gráfico de formação de subgrupos, apresenta um subgrupo em cor vermelha que predomina; no entanto, as cores verdes e amarelas sugerem o intercâmbio genético com os demais plantéis. Por último, o plantel de Teresina mostra uma maior homogeneidade genética, talvez por causa da formação deste plantel, que foi formado maiormente por indivíduos do Município de Queimada Nova. Isso sugere, também, que esta população pode estar sofrendo um processo de gargalo de garrafa em virtude da formação de uma população com um número pequeno de reprodutores. A distância geográfica também pode estar influenciando o intercâmbio de material genético entre os plantéis.

A análise bayesiana revela que nos plantéis estudados há presença de indivíduos similares, de origem comum, entre as localidades avaliadas. Ou seja, está ocorrendo fluxo gênico entre as populações. Esse fato se justifica pelo fato de os plantéis de Canela-Preta estudados pertencerem a um programa que pratica intercâmbio de reprodutores, propiciando conexão genética entre as populações amostradas.

Os resultados obtidos neste trabalho fornecem subsídios para diversas investigações acerca das galinhas crioulas Canela-Preta nos municípios do Piauí e sugerem um possível estudo em outros estados, especialmente na área genética, na qual os trabalhos com marcadores moleculares ainda são escassos. Os índices

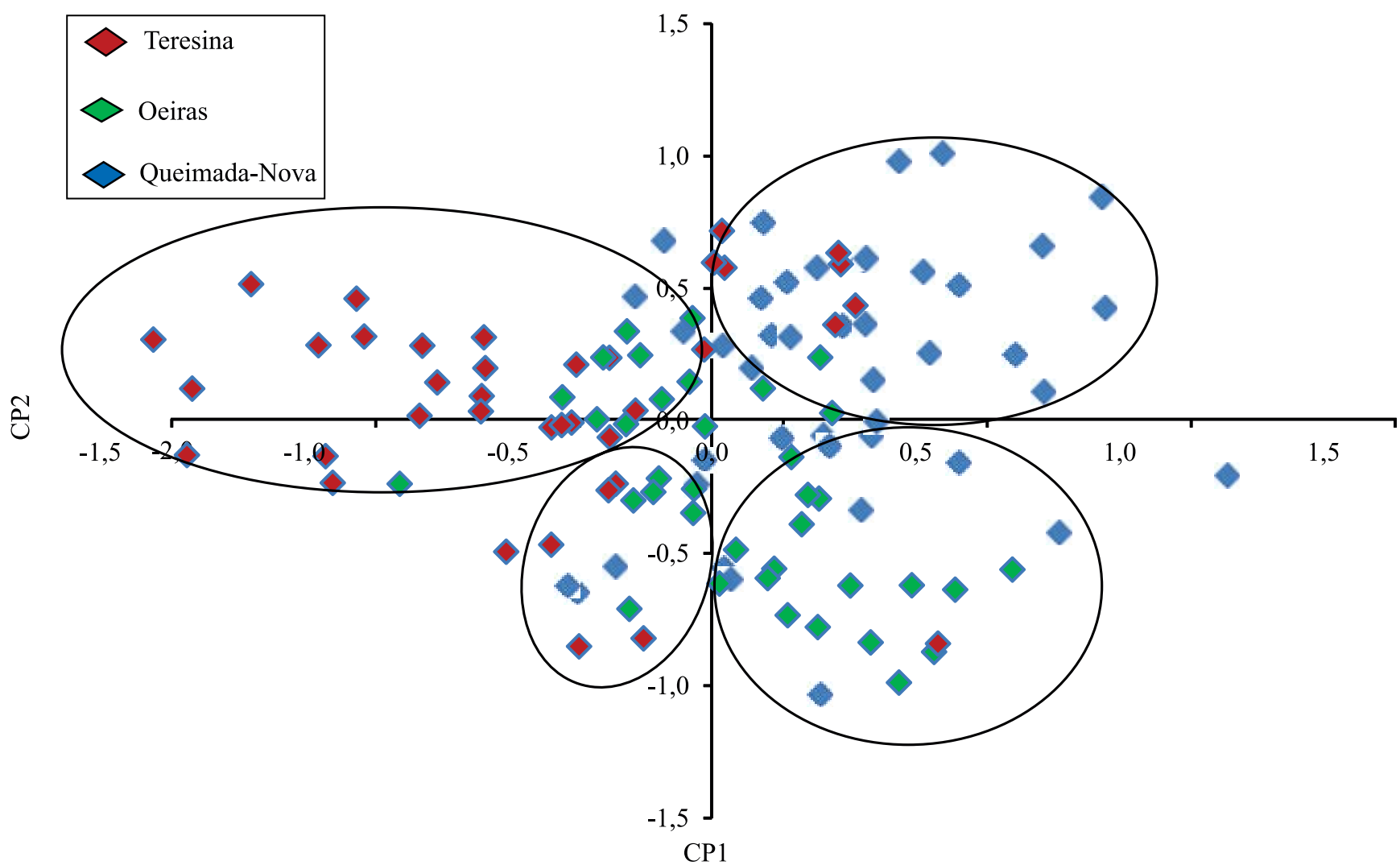

Figura 1. Dispersão gráfica das distâncias intrapopulacionais dos três plantéis de galinhas Canela-Preta (Teresina, Oeiras e Queimada Nova) em relação aos eixos cartesianos estabelecidos pelos componentes principais (CP1 e CP2), baseada na matriz de dissimilaridade. 

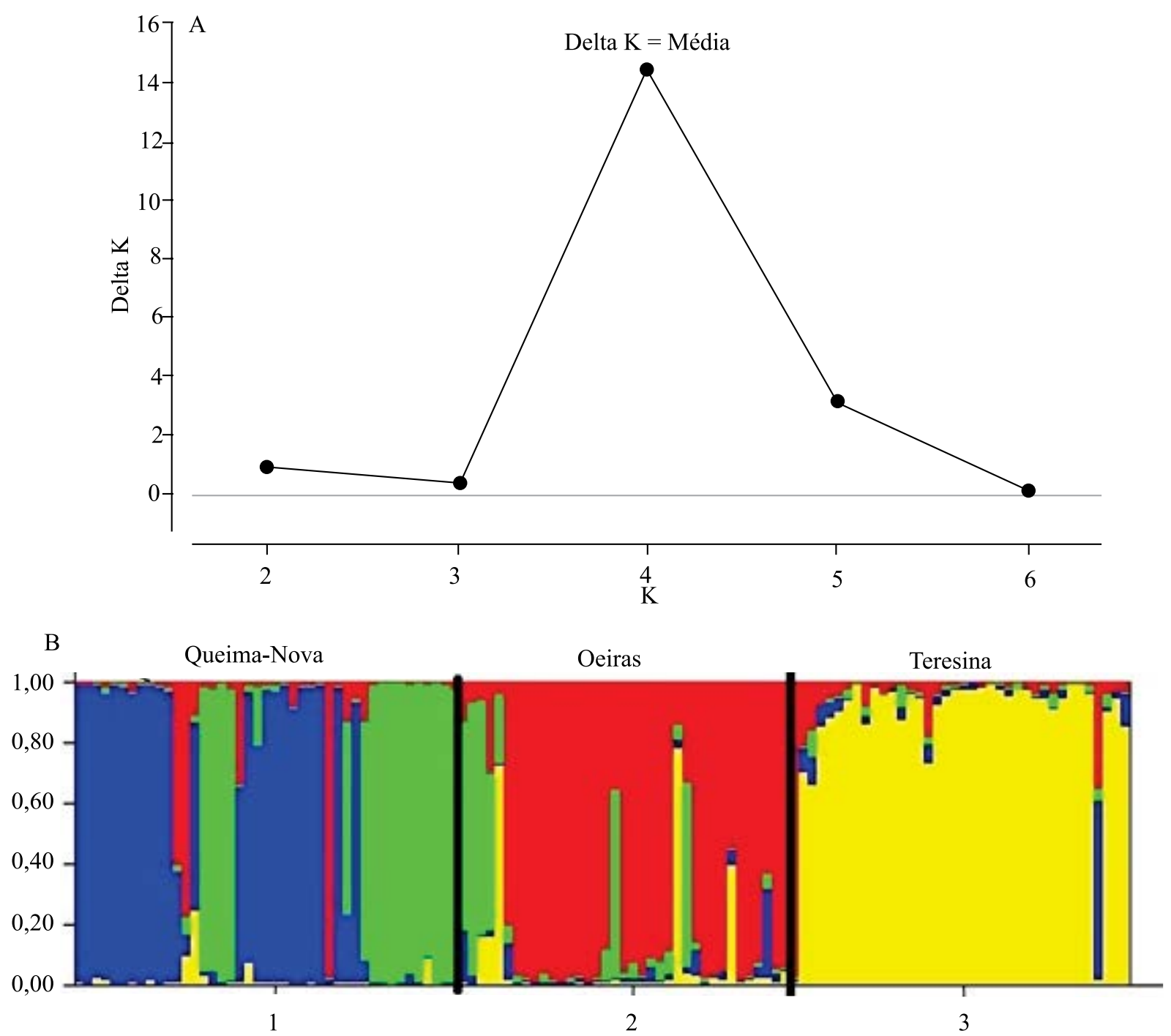

Figura 2. Representação gráfica do valor de K para a formação de grupos de galinhas Canela-Preta (A) e análise de estrutura populacional de 118 indivíduos, representando quatro grupos de galinhas Canela-Preta com base em 12 marcadores de microssatélites (B). Cada grupo está representado por uma cor específica. O eixo y exibe a ascendência estimada de cada indivíduo em um determinado grupo ou subpopulação, usando o modelo de mistura.

endogâmicos reportados e fluxo gênico entre os animais amostrados podem indicar uma possível preocupação em conservar a variabilidade das galinhas crioulas Canela-Preta, sugerindo realização de programas específicos de acasalamentos entre esses animais.

\section{Conclusões}

1. Os três plantéis estudados de galinhas CanelaPreta no Estado do Piauí exibem uma baixa diferenciação genética e evidenciam um excesso de homozigose; no entanto, esta raça apresenta uma elevada variabilidade genética.
2. O plantel de Teresina apresenta o processo de efeito fundador em virtude do histórico de formação do plantel, com predominância de um subgrupo, distância geográfica, e maior valor de índice de endogamia quando comparado com os outros plantéis.

\section{Agradecimentos}

À Coordenação de Aperfeiçoamento de Pessoal de Nível Superior (Capes), à Fundação de Amparo à Pesquisa do Estado de Minas Gerais (Fapemig), pelo apoio financeiro, à Embrapa Meio Norte e ao Projeto "Produtores do Futuro". 


\section{Referências}

ABEBE, A.S.; MIKKO, S.; JOHANSSON, A.M. Genetic diversity of five local swedish chicken breeds detected by microsatellite markers. Plos One, v.10, p.1-13, 2015. DOI: 10.1371/journal. pone. 0120580 .

BASSAM, B.J.; CAETANOANOLLÉS, G.; GRESSHOFF, P.M. Fast and sensitive silver staining of DNA in polyacrylamide gels. Analytical Biochemistry, v.196, p.80-83, 1991. DOI: 10.1016/00032697(91)90120I.

CHATTERJEE, R.N.; BHATTACHARYA, T.K.; DANGE, M.; DUSHYANTH, K.; NIRANJAN, M.; REDDY, B.L.N.; RAJKUMAR, U. Genetic heterogeneity among various Indigenous and other chicken populations with microsatellite markers. Journal of Applied Animal Research, v. 43, p.266-271, 2015. DOI: $10.1080 / 09712119.2014 .963097$.

CLEMENTINO, C. de S. Caracterização genética de galinhas naturalizadas na região meionorte do Brasil, com uso de microssatélites. 2010. 93p. Dissertação (Mestrado) - Universidade Federal do Piauí, Teresina.

DAS, A.K.; KUMAR, S.; RAHIM, A. Estimating microsatellite based genetic diversity in Rhode Island Red chicken. Iranian Journal of Veterinary Research, v.16, p.274-277, 2015.

DÁVILA, S.G.; GIL, M.G.; RESINOTALAVÁN, P.; CAMPO, J.L. Evaluation of diversity between different Spanish chicken breeds, a tester line, and a White Leghorn population based on microsatellite markers. Poultry Science, v.88, p.2518-2525, 2009. DOI: $10.3382 /$ ps.200900347.

EVANNO, G.; REGNAULT, S.; GOUDET, J. Detecting the number of clusters of individuals using the software STRUCTURE: a simulation study. Molecular Ecology, v.14, p.2611-2620, 2005. DOI: 10.1111/j.1365294X.2005.02553.x.

EXCOFFIER, L.; SMOUSE, P.E.; QUATTRO, J.M. Analysis of molecular variance inferred from metric distances among DNA haplotypes: applications to human mitochondrial DNA restriction data. Genetics, v.131, p.479-491, 1992.

FAVATI, A.; LEIMAR, O.; LOVLIE, H. Personality predicts social dominance in male domestic fowl. Plos One, v.9, p.1-7, 2014. DOI: 10.1371/journal.pone.0103535.

FONTEQUE, G.V.; BATTILANA, J.; PALUDO, E.; LIMAROSA, C.A. da V. Genetic polymorphism of fifteen microsatellite loci in Brazilian (blueegg Caipira) chickens, Pesquisa Veterinária Brasileira, v.34, p.98-102, 2014. DOI: 10.1590/ S0100736X2014000100016.

HARTL, D.L.; CLARK, A.G. Principles of population genetics. $3^{\text {rd }}$ ed. Sunderland: Sinauer, 2010. 481p.

KAYA, M.; YILDIZ, M.A. Genetic diversity among turkish native chickens, denizli and gerze, estimated by microsatellite markers. Biochemical Genetics, v.46, p.480-491, 2008. DOI: 10.1007/s10528-008-9164-8.

KUMAR, V.; SHUKLA, S. K.; MATHEW, J.; SHARMA, D. Genetic diversity and population structure analysis between indian red jungle fowl and domestic chicken using microsatellite markers. Animal biotechnology, v.26, p.201-210, 2015. DOI: 10.1080/10495398.2014.983645.

LOPERA-BARRERO, N.M.; POVH, J.A.; RIBEIRO, R.P.; GOMES, P.C.; JACOMETO, C.B. LOPES, T. da S. Comparación de protocolos de extracción de ADN con muestras de aleta y larva de peces: extracción modificada con cloruro de sodio. Ciencia e Investigación Agraria, v.35, p.77-86, 2008c. DOI: 10.4067/ S071816202008000100008.

MARIANTE, A. da S.; EGITO, A.A.; ALBUQUERQUE, M. do S.M.; PAIVA, S.R.; RAMOS, A.F. Managing genetic diversity and society needs. Revista Brasileira de Zootecnia, v.37, p.127-136, 2008. Suplemento especial. DOI: 10.1590/ S151635982008001300016.

MCMANUS, C.; PAIVA, S.; CORRÊA, P.S.; SEIXAS, L.; MELO, C.B. de. Estatísticas para descrever genética de populações. 2011. Disponível em: <http://www.animal.unb.br/ images/Serie tecnica_genetica_populacoes_atual.pdf $>$. Acesso em: 7 abr. 2016.

MUCHADEYI, F.C.; EDING, H.; WOLLNY, C.B.A.; GROENEVELD, E.; MAKUZA, S.M.; SHAMSELDIN, R.; SIMIANER, H.; WEIGEND, S. Absence of population substructuring in Zimbabwe chicken ecotypes inferred using microsatellite analysis. Animal Genetics, v.38, p.332-339, 2007. DOI: 10.1111/j.13652052.2007.01606.x.

PEAKALL, R.; SMOUSE, P.E. GenAlEx 6.5: genetic analysis in Excel. Population genetic software for teaching and researchan update. Bioinformatics, v.28, p.2537-2539, 2012. DOI: 10.1093/ bioinformatics/bts 460 .

PRITCHARD, J.K.; STEPHENS, M.; DONNELLY, P. Inference of population structure using multilocus genotype data. Genetics, v.155, p.945-959, 2000.

QU, L.; LI, X.; XU, G.; CHEN, K.; YANG, H.; ZHANG, L.; WU, G.; HOU, Z.; XU, G.; YANG, N. Evaluation of genetic diversity in Chinese indigenous chicken breeds using microsatellite markers. Science in China Series C: Life Sciences, v.49, p.332341, 2006. DOI: $10.1007 / \mathrm{s} 1142700620016$.

RENGMARK, A.H.; SLETTAN, A.; SKAALA, O.; LIE, O.; LINGAAS, F. Genetic variability in wild and farmed Atlantic salmon (Salmo salar) strains estimated by SNP and microsatellites. Aquaculture, v.253, p.229-237, 2006. DOI: 10.1016/j.aquaculture.2005.09.022.

WRIGHT, S. The genetical structure of populations. Annals of Eugenics, v.15, p.323-354, 1949. DOI: 10.1111/j.1469-1809.1949. tb02451.x..

Recebido em 3 de maio de 2016 e aprovado em 22 de julho de 2016 